\title{
Evaluation of the role of the contractor's personnel in enhancing the project constructability
}

\begin{abstract}
Contractors' personnel play a prominent role in enhancing the constructability of facilities design, construction and assessment. Looks at the constructability concepts identified by the Construction Industry Institute at Austin, Texas (CII) and represents and describes the constructability concepts in relation to contractors' personnel. Discusses the role of each of them in enhancing constructability of facilities projects. Concludes that a set of obligations are the answer to the question of "How can the contractor's personnel enhance the project constructability?".
\end{abstract}

Keyword: Buildings, Construction management, Facilities management, Personnel, Planning 